\title{
Stress-induced cardiomyopathy
}

\author{
J.M. van Opstal, E.C. Cheriex
}

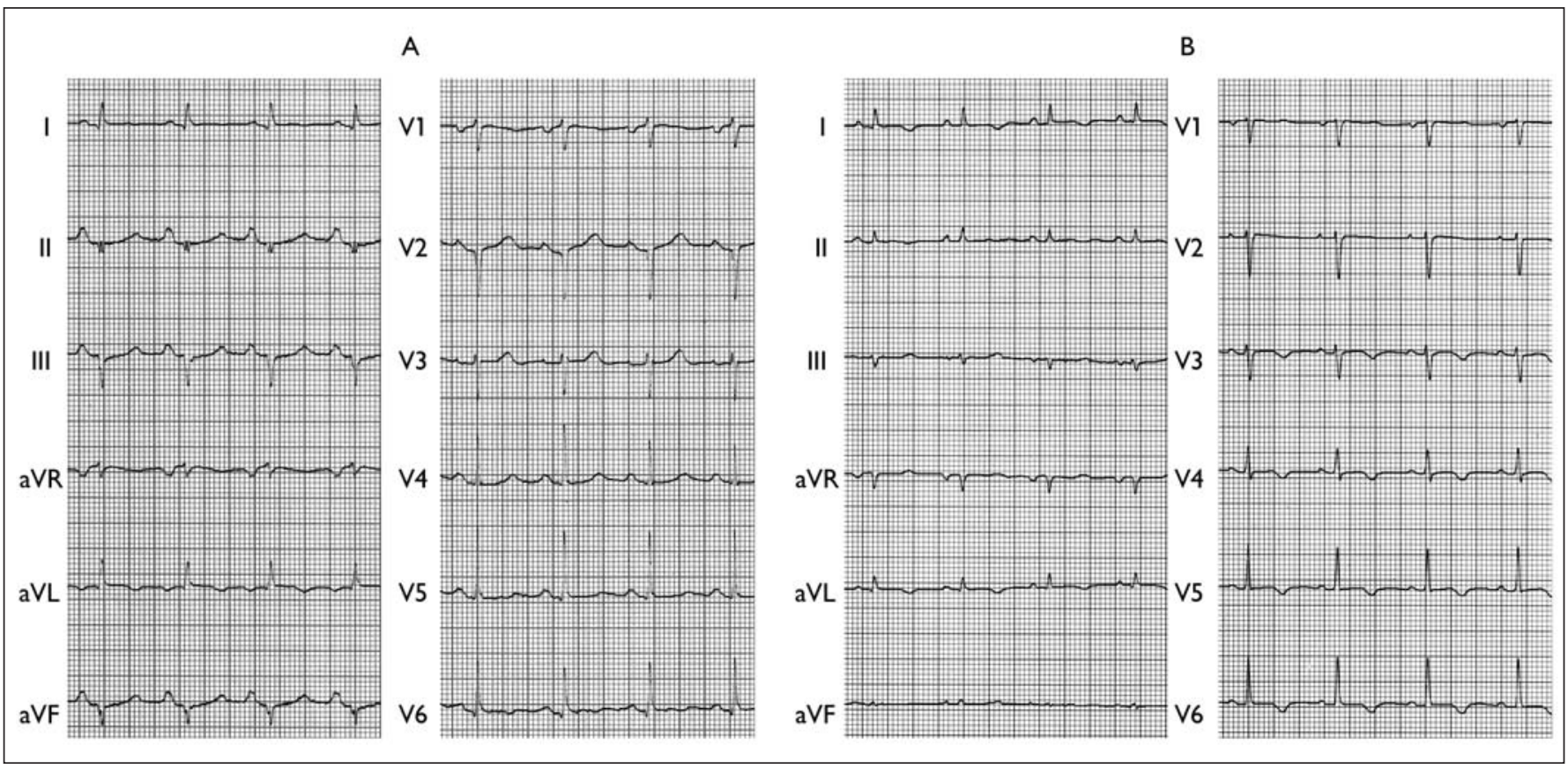

Figure 1. ECG during Takotsubo cardiomyopathy (panel A) and after resolvement of cardiac dysfunction (panel B, see also text)

A 58-year-old female presented with typical chest pain, which had started a week ago. She presented late because she first suspected that her symptoms were due to severe stress related to the terminal illness of her father.

The ECG (figure 1, panel A) demonstrated a left axis, $Q$ waves and conduction delay in the inferior leads, poor $\mathrm{R}$ wave progression in the precordial leads and abnormal STT segments. The troponin T levels were also elevated. Because an acute coronary syndrome was suspected, an emergent coronary angiogram was performed, which surprisingly demonstrated normal epicardial coronaries.

The echocardiogram (movie, left panel), however, indicated a poor left ventricular (LV) function (LV ejection fraction approximately $20 \%$ ) with apical

\section{J.M. van Opstal \\ E.C. Cheriex \\ Department of Cardiology, Maastricht University Hospital, Maastricht, the Netherlands}

Correspondence to: J.M. van Opstal

Department of Cardiology, Maastricht University Hospital, PO Box 5800, 6202 AZ Maastricht, the Netherlands

E-mail: jmvanopstal@yahoo.com ballooning and only contraction of the basal segments.

After a week the LV function had normalised (movie, right panel) and the ECG markedly improved with normal conduction but development of negative $\mathrm{T}$ waves in the precordial leads (figure 1 , panel $\mathrm{B}$ ). This clinical presentation and course is consistent with Takotsubo cardiomyopathy, and also demonstrates that cardiac conduction can be affected in this disease.

Takotsubo cardiomyopathy was first described in Japan, and the name of the disorder is taken from the Japanese name for an octopus trap (Tako-tsubo), which has a similar configuration to LV apical ballooning. The onset is typically triggered by acute medical illness or intense emotional or physical stress. ${ }^{1}$ The pathogenesis is not well understood but the prognosis is relatively good (mortality $<1 \%$ ). ${ }^{1}$ Despite the severity of the acute illness Takotsubo cardiomyopathy can be managed by supportive therapy as it is a transient disorder.

Moving images illustrating this condition are shown on the journal's website at www.cardiologie.nl.

\section{References}

I Tsuchihashi K, Ueshima K, Uchida T, Oh-mura N, Kimura K, Owa M, et al. Transient left ventricular apical ballooning without coronary artery disease: a novel heart syndrome mimicking acute myocardial infarction. Angina Pectoris Myocardial infarction Investigations in Japan. J Am Coll Cardiol 2001;38:11. 